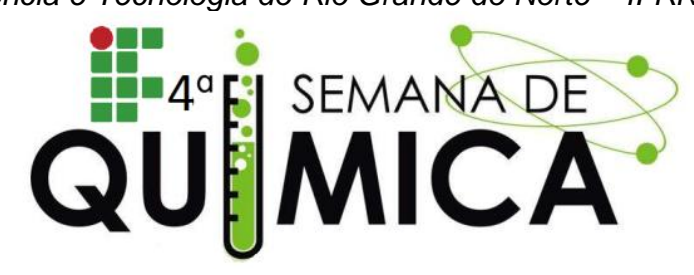

\title{
RECUPERAÇÃO DA PRATA RESIDUAL DAS TITULAÇÕES ARGENTIMÉTRICAS REALIZADAS EM AULA DE QUÍMICA ANALITICA QUANTITATIVA.
}

OLIVEIRA, R. A. (IC) (IFRN-NC), AMARAL, S. J.X.O. (IC) (IFRN-NC), SILVA, A. C. O (PQ) (IFRN-NC).

Palavras Chave: Tratamento de resíduo, titulação argentimétrica, prata.

\section{INTRODUÇÃO}

Os laboratórios de ensino, em especial os Departamentos de Química Analítica, têm sido um dos responsáveis por gerar volumes de resíduos químicos, muitas vezes desconhecidos e sem o armazenamento apropriado. Os resíduos recuperados podem ser reutilizados no mesmo processo em que foram gerados, ou se transformar em matéria prima para outros processos. Este trabalho tem como objetivo tratar e reaproveitar a prata oriunda de experimentos argentimétricos, o método de Mohr, do laboratório de ensino de química analítica do IFRN, Campus Nova Cruz ${ }^{[1]}$.

\section{METODOLOGIA}

O tratamento, recuperação da prata metálica e reaproveitamento para nitrato de prata são apresentados no fluxograma ${ }^{[1,2]}$.

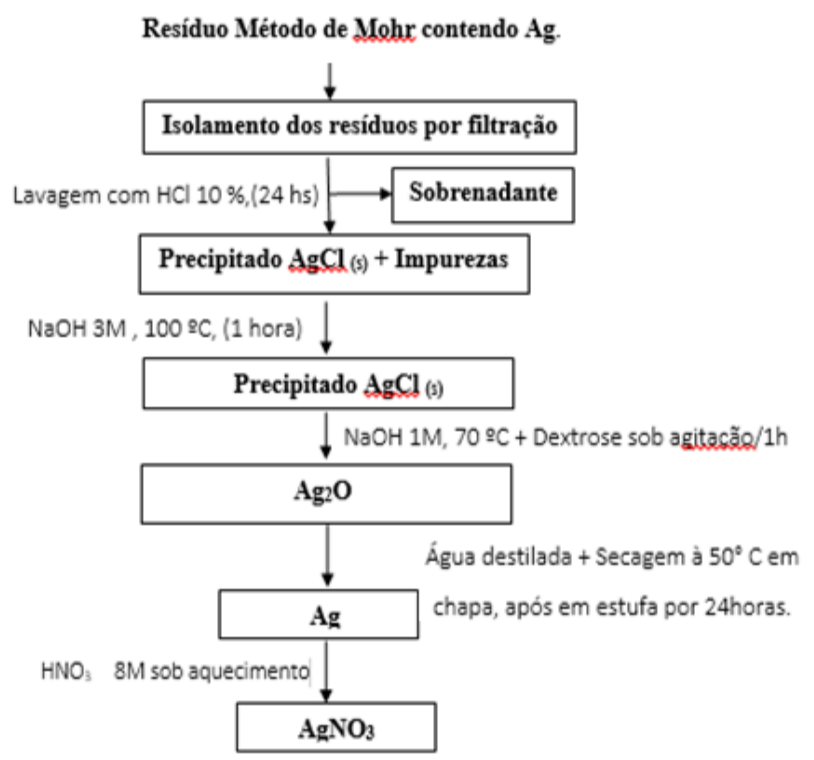

\section{Caracterização de $\mathrm{AgNO}_{3}$}

A caracterização foi realizada por titulação argentimétrica, em que 0,1 $\mathrm{M} \mathrm{AgNO}_{3}$ foi submetida a padronização com $\mathrm{NaCl}$ 0,1 M na presença de $\mathrm{K}_{2} \mathrm{CrO}_{4} 5 \%$ como indicador.

\section{RESULTADOS E DISCUSSÕES}

A tabela 1 mostra o rendimento do processo de recuperação da prata.

Tabela 1 - Rendimento da recuperação de prata residual do método de Mohr.

\begin{tabular}{c|c|c|c}
\hline Amostra & $\mathrm{Ag}_{\text {residual }}$ & $\mathrm{Ag}_{\text {recuperada }}$ & Rendimento \\
\hline $\mathrm{A}$ & $1,1766 \mathrm{~g}$ & $1,1522 \mathrm{~g}$ & $97,92 \%$ \\
\hline $\mathrm{B}$ & $0,7334 \mathrm{~g}$ & $0,7238 \mathrm{~g}$ & $98,69 \%$ \\
\hline
\end{tabular}

A análise quantitativa mostra resultados satisfatórios conforme a Tabela 2, com teor de $\mathrm{AgNO}_{3}$ de 95\% na titulação.

Tabela 2 - Volumes gastos na titulação com a solução de $\mathrm{AgNO}_{3}$ 0,1M

\begin{tabular}{c|c}
\hline \multicolumn{2}{c}{ Volume gasto de $\mathrm{AgNO}_{3}$ na titulação de $\mathrm{NaCl}$} \\
\hline Volume teórico & $10,0 \mathrm{~mL}$ \\
\hline Volume experimental $\mathrm{AgNO}_{3}$ P.A. & $10,1 \mathrm{~mL}$ \\
\hline Volume experimental $\mathrm{AgNO}_{3}$ reciclado & $10,5 \mathrm{~mL}$ \\
\hline
\end{tabular}

\section{CONCLUSÃO}

Diante dos resultados, as amostras de $\mathrm{AgNO}_{3}$ tratadas, poderão ser reutilizadas nas aulas de Química Analítica Quantitativa.

\section{REFERÊNCIAS}

1 AMARAL et al. Relato de uma experiência: Recuperação e cadastramento de resíduos dos laboratórios de graduação do Instituto de Química da Universidade Federal do Rio Grande do Sul. Revista Quím. Nova, v. 24, n.3, 2001.

2 GOMES, M. G. et al. Tratamento, recuperação, reaproveitamento de resíduos químicos gerados em laboratórios de ensino da UFC. Rev. Universo \& Extensão, v. 1, n.1, 2013. 